Resumos de Trabalhos de Conclusão de Curso do Bacharelado em Teologia da Pontifícia Universidade Católica do Paraná, Campus Curitiba, defendidos em 2020

Abstracts of the Undergraduate final monographs in Theology defended in 2020 at the Pontifical Catholic University of Paraná

Vários Autores*

*A disciplina de Trabalho de Conclusão de Curso foi coordenada pela Profa. Dra. Jaci de Fátima Souza Candiotto. 


\title{
O DIÁLOGO INTER-RELIGIOSO NO MOVIMENTO DOS FOCOLARES
}

Autor: Ailton Lima de Paula ${ }^{1}$ Orientador: Joachim Andrade ${ }^{2}$

\begin{abstract}
Resumo
A abordagem desta pesquisa se justifica pelo atual panorama mundial, de profunda transformação rumo a uma sociedade cada vez mais multicultural e multirreligiosa. É nesse contexto que o Movimento dos Focolares está empenhado em promover o diálogo entre as religiões, a fim de que o pluralismo religioso da humanidade não seja causa de divisões e guerras, mas contribua para a construção da fraternidade e da paz no mundo. O objetivo deste estudo é apresentar o diálogo que o Movimento dos Focolares promove, que é fundamentado na espiritualidade e, em particular, na centralidade do amor, contextualizando o trabalho do diálogo inter-religioso e os novos desafios na contemporaneidade, analisando de que maneira é realizado esse diálogo no tempo presente e averiguando se o trabalho inter-religioso no Movimento dos Focolares poderá servir de modelo para o diálogo nos tempos atuais. Esta tarefa foi obtida por meio de pesquisas bibliográficas, literatura especializada na área da Teologia, baseada nas reflexões teológicas, sob referencial do método dedutivo. A análise demostrou que, segundo a metodologia usada pelo Movimento dos Focolares, devemos compreender a profundidade do diálogo, preservando as diferenças, e que só no amor encontramos uma resposta, pois a doutrina vem em um segundo momento: primeiro vem o amor, a reciprocidade, a liberdade e o respeito à diferença.
\end{abstract}

Palavras-chave: Diálogo. Inter-religioso. Movimento dos Focolares.

\footnotetext{
${ }^{1}$ Bacharel em Teologia pela Pontifícia Universidade Católica do Paraná (2020). E-mail: ivofaraujo@gmail.com

2 Doutor em Ciências da Religião pela Pontifícia Universidade Católica de São Paulo (PUC-SP). Docente da Pontifícia Universidade Católica do Paraná (PUCPR). Contato: joachimandrade@terra.com.br
} 


\title{
A UNIDADE DOS SACRAMENTOS DA INICIAÇÃO CRISTÃ
}

Autor: Anderson Correa da Silva ${ }^{3}$ Orientador: Roberto Nentwig ${ }^{4}$

\begin{abstract}
Resumo
Este artigo analisa a íntima unidade dos Sacramentos da Iniciação à Vida Cristã, e sua relação com os Mistérios da Páscoa e de Pentecostes. Esses sacramentos desde o princípio da Igreja são formados pelo Batismo, Confirmação e Eucaristia, nesta ordem e unidade. No decorrer da história houve uma separação temporal e quase um abandono da unidade interna e teológica que esses são constituídos. O objetivo do artigo é explicitar a íntima unidade desses sacramentos em uma única economia da salvação. Fundamenta a unidade e a ordem sacramental, e verifica as possibilidades de uma nova compreensão e vivência pastoral. A metodologia utilizada foi a qualitativa, predominantemente bibliográfica. Com este artigo buscamos expressar que "A Iniciação à Vida Cristã é a participação humana no diálogo da salvação." (CNBB, 107, n. 96). Partimos da Páscoa e Pentecostes como integrantes do único mistério salvífico. E na reflexão percorrida afirmamos que o Batismo e Crisma são inseparáveis, assim como o Mistério Pascal e Pentecostes. Por sua vez, buscamos situar a Eucaristia, como ápice da vida cristã. Percebemos que há modelos históricos que salvaguardam a unidade e a ordem sacramental original, e a sintonia com os mistérios celebrados. Diante disso, apontamos possibilidades de mudança da ordem no caso da iniciação de adolescentes, e no caso de adultos incentivamos o processo catecumenal proposto pelo Vaticano II - essas perspectivas garantem um processo de iniciação que salvaguarde a unidade interna e a ordem original com um resgate pneumatológico, unido ao Mistério Pascal.
\end{abstract}

Palavras-chave: Iniciação à Vida Cristã. Páscoa. Pentecostes. Catecumenato

\footnotetext{
${ }^{3}$ Bacharel em Filosofia pela FAVI e Bacharel em Teologia pela Pontifícia Universidade Católica do Paraná.

${ }^{4}$ Doutor em Teologia pela PUC-RJ (2017). Docente da Pontifícia Universidade Católica do Paraná (PUCPR) e no Studium Theologicum em Curitiba. Contato: beto.catequese@gmail.com.
} 


\title{
MICHEL DE CERTEAU: A MÍSTICA DO COTIDIANO
}

Autor: Breno Cesar Carvalho de Souza ${ }^{5}$ Orientadora: Andréia Cristina Serrrato ${ }^{6}$

\begin{abstract}
Resumo
Pesquisar Michel de Certeau é propor uma nova conceituação em vários aspectos, mas, especialmente nas áreas da Cultura, da Mística e da História, com bases antropológicas, que incidem na maneira de ser, fazer e assumir a teologia, especialmente a teologia pública, nos últimos tempos. O objetivo central é estabelecer o diálogo da Cultura nas categorias elencadas pelo autor e perceber sua aplicabilidade ou indicação de relação com a pluralidade temática e na reconstrução conceitual. Metodologia descritiva bibliográfica utilizamos as leituras, orientações, grupos de estudos e aulas sobre a temática e o autor. Os materiais em foco foram as obras de Certeau, especialmente A fábula mística, A Cultura no Plural e a Invenção do Cotidiano. Um dos grandes resultados é a visita ao conteúdo da epistemologia negativa como fonte de conhecimento pela via da negação ou mesmo da descida ao não conhecimento ao conhecimento. É uma via alternativa e diferente daquilo que muitos outros autores se conduzem a percorrer. Para Certeau, a epistemologia se traduz como uma linguagem teológica da kénosis, num rebaixamento ou mesmo de um esvaziamento para o preencher-se absolutamente. Pesquisar Certeau é, propriamente, um desafio. Contudo, um desafio que não pode resumir-se às limitações da difícil compreensão, mas da abertura que se estabelece em vista das novas maneiras de conhecer e, por consequência, viver.
\end{abstract}

Palavras-chave: Cotidiano. Mística. Outro.

\footnotetext{
${ }^{5}$ Bacharel em Teologia pela Pontifícia Universidade Católica do Paraná.

${ }^{6}$ Doutora em Teologia pela Pontifícia Universidade Católica do Rio de Janeiro (2015). Docente da Pontifícia Universidade Católica do Paraná (PUCPR). Contato: andreia.serrato@pucpr.br.
} 


\title{
ESTUDO COMPARATIVO DAS VIAS DE EVANGELIZAÇÃO DA EVANGELLI NUNTIANDI COM A EVANGELLI GAUDIUM, UM OLHAR PARA A ATUALIDADE
}

Autor: Clairton Luis da Silva ${ }^{7}$ Orientador: Cesar Leandro Ribeiro ${ }^{8}$

\begin{abstract}
Resumo
O presente artigo analisa a exortação apostólica Evangelli Nuntiandi de Paulo VI, confrontandoa com a exortação Evangelli Gaudium, do Papa Francisco, buscando um olhar para a atualidade. Esta abordagem comparativa se detém nas vias de evangelização que ambas abordam, destacando os tópicos que refletem uma necessidade de anúncio da Palavra, que perpassa um simples falar. Como resultado final, pretende-se com esse estudo, por meio da metodologia de pesquisa bibliográfica, a identificação de consonância entre esses dois documentos pontifícios, tendo em vista a grande evolução que a comunicação vem sofrendo nesses anos que as separam. Além disso, pretende-se evidenciar as vias de evangelização que tratam do anúncio da Palavra por uma pregação viva e mass media. Esta reflexão permite perceber a necessidade da ampliação do horizonte teológico na busca de alternativas próprias de cada tempo e, sobretudo, da necessidade de atualizar a forma de evangelização para os desafios que marcam a Igreja conduzida por Francisco. As grandes mudanças tecnológicas e o fácil acesso à informação demonstraram que o ser humano tem buscado referências humanas, líderes, comunicadores que façam apologia à sua fé, à sua doutrina. Diante disso, pôde-se perceber que o anúncio da Palavra continua sendo uma realidade viva, única, necessária. É o próprio ser humano que empresta sua voz para ser a voz de Cristo, se valendo das vias de evangelização descritas nessas exortações, as quais, fundamentam esse trabalho.
\end{abstract}

Palavras-chave: Anúncio. Evangelização. Palavra. Meios de comunicação.

\footnotetext{
${ }^{7}$ Bacharel em Teologia pela Pontifícia Universidade Católica do Paraná.

${ }^{8}$ Doutor em Teologia pela Pontifícia Universidade Católica do Paraná (2018). Docente da Pontifícia Universidade Católica do Paraná (PUCPR).
} 


\title{
A ESPIRITUALIDADE NAS COMUNIDADES TERAPÊUTICAS PARA USUÁRIOS DE ÁLCOOL E OUTRAS DROGAS
}

Autor: Cleverson Luis Nogueira9 Orientador: Marcio Luiz Fernandes ${ }^{10}$

\begin{abstract}
Resumo
Este trabalho analisa como a espiritualidade torna-se um recurso significativo na vida de usuários de álcool e outras drogas que se encontram em tratamento em Comunidades Terapêuticas. É significativo o aumento de pesquisas sobre a relação entre espiritualidade e saúde integral do ser humano. Tanto a espiritualidade quanto a religiosidade se consideradas como horizonte de sentido e propósito para a vida podem ser grandes aliadas para ajudar os dependentes químicos e servir como fator de proteção, prevenção e ajuda na hora do tratamento e manutenção da abstinência. O objetivo deste trabalho é compreender as diversas formas, métodos e aplicações da espiritualidade e da religiosidade no tratamento e acompanhamento dos acolhidos nas Comunidades Terapêuticas. Este propósito será conseguido mediante a pesquisa de forma dedutiva por meio de mídias eletrônicas, revistas, livros, apostilas e em Comunidades Terapêuticas. A pesquisa demonstrou que o tratamento terapêutico obtém maior resultado em porcentagem quando é aplicada a espiritualidade e a religiosidade como parte dele, considerando a metodologia das casas, trabalhada pelos profissionais e técnicos no desenvolvimento do programa inserido.
\end{abstract}

Palavras-chave: Espiritualidade. Religiosidade. Dependência Química.

\footnotetext{
${ }^{9}$ Bacharel em Teologia pela Pontifícia Universidade Católica do Paraná.

${ }^{10}$ Doutor em Teologia pela Pontifícia Universidade Lateranense - Doutor em Psicologia pela USP. Docente da Pontifícia Universidade Católica do Paraná (PUCPR).
} 


\title{
DIÁLOGO ECUMÊNICO E A CASA COMUM
}

Autor: Cristiano Ferreira Gozdeck ${ }^{11}$

Orientador: Joachim Andrade ${ }^{12}$

\begin{abstract}
Resumo
O Brasil é um país de extensão continental com uma imensa diversidade de fauna e flora, que vem sendo degradada ao logo dos anos, por isso é urgente que a população tenha consciência de sua responsabilidade na preservação do meio, a degradação ecológica afeta a todos, sejam católicos, cristãos de outras denominações e pessoas de outras religiões. Nesse contexto é fundamental que haja um diálogo maior entre os cristãos em nosso país com a finalidade de preservar a Casa Comum. Objetiva-se lançar luzes às ações ecumênicas no Brasil, que visam a proteção do meio ambiente, a casa comum e as ações que vem aproximando católicos e cristãos de outras denominações. Método: Dedutivo, qualitativo, descritivo e de revisão bibliográfica. Resultados: As Campanhas da Fraternidade realizadas anualmente pela CNBB, atingem um grande percentual da população brasileira, sempre com temas que são sensíveis á sociedade, dentre eles a questão ambiental. Conclusão: Desde o ano 2000 a CNBB e o CONIC realizam a cada cinco anos a edição ecumênica da campanha da fraternidade, que em 2016 tratou sobre a conscientização de seus fiéis sobre o zelo pela casa comum. Com isso, o diálogo ecumênico no país vem se fortalecendo e buscando novas ações na busca de uma ecologia integral proposta pelo Papa Francisco.
\end{abstract}

Palavras-chave: Ecumenismo. Casa Comum. Ecologia. Campanhas da Fraternidade Ecumênicas.

${ }^{11}$ Bacharel em Teologia pela Pontifícia Universidade Católica do Paraná.

12 Doutor em Ciências da Religião pela Pontifícia Universidade Católica de São Paulo (PUC-SP). Docente da Pontifícia Universidade Católica do Paraná (PUCPR). Contato: joachimandrade@terra.com.br. 


\title{
ASSISTÊNCIA ESPIRITUAL A QUEM CUIDA: QUESTÃO PARA A TEOLOGIA
}

Autora: Elizangela de Souza Schneider Maciel ${ }^{13}$ Orientadora: Marcia Regina Chizini Chemin ${ }^{14}$ Orientadora: Mary Rute Gomes Esperandio ${ }^{15}$

\begin{abstract}
Resumo
A assistência espiritual a familiares que assumem a função de cuidadores/as informais de pessoas enfermas em Cuidados Paliativos está prevista nessa abordagem terapêutica, pois faz parte cuidar também da família de pacientes. O objetivo deste estudo foi identificar a literatura científica sobre a assistência espiritual a familiares em Cuidados Paliativos; se esta é atribuída a profissionais, e se aparece como possibilidade de prática teológica. Procedeu-se uma revisão integrativa de literatura, com busca de artigos na Scientific Electronic Library Online e no Portal da Biblioteca Virtual em Saúde, publicados entre julho de 2015 e julho de 2020, em português, disponíveis na íntegra. Foram localizados 18 artigos, dos quais cinco foram selecionados para análise. Evidenciou-se que se considera importante a atenção aos aspectos espirituais durante os Cuidados Paliativos, porém não se aponta o que é assistência espiritual e não a relaciona a um campo específico do conhecimento/formação profissional; profissionais dos cuidados de Saúde cogitam a possibilidade de assumir a função, mas reconhecem sua limitação para essa atividade; nenhum dos artigos abordou a atenção espiritual a cuidadores/as familiares durante os Cuidados Paliativos. Concluiu-se que há pouca pesquisa sobre o tema, entretanto, os aspectos espirituais das pessoas não podem ser negligenciados. A Teologia, especialmente por meio da formação acadêmica, poderá contribuir na provisão de pessoal para atuação em assistência espiritual a pessoas que exercem cuidado de outras.
\end{abstract}

Palavras-chave: Assistência espiritual em cuidados paliativos. Cuidadores familiares. Teologia.

\footnotetext{
${ }^{13}$ Bacharela em Teologia pela Pontifícia Universidade Católica do Paraná.

14 Doutora em Teologia pela PUCPR.

${ }^{15}$ Doutora em Teologia. Docente da Pontifícia Universidade Católica do Paraná (PUCPR).
} 


\title{
O AGIR FRATERNO NO PROJETO DE CHIARA LUBICH COMO PRINCÍPIO BIBLÍCO DE HUMANIZAÇÃO
}

\author{
Autor: Everton luiz dos Santos ${ }^{16}$ \\ Orientadora: Jaci de Fátima Souza Candiotto ${ }^{17}$
}

\begin{abstract}
Resumo
O presente artigo enseja fazer um estudo introdutório nos escritos de Chiara Lubich dado a importância deles enquanto prospostas de vivências humanas pautadas no espírito do Evangelho. Considerando o contexto em que vivemos, marcado pela desigualdade social e deturpação na vivência dos valores humanos e evangélicos, vislumbramos no programa da Econômia de Comunhão e no Amor Social que nutre o projeto de Chiara Lubich uma perspectiva salutar para alavancar políticas públicas de enfrentamento aos problemas sociais que tem dificultado relações humanas mais inclusivas e menos indiferentes aos excluídos da história. 0 objetivo de nossa pesquisa, portanto, é demonstrar que a proposta do agir fraterno, do projeto da Economia de Comunhão, proposto por Chiara Lubich, constitui o princípio bíblico de humanização por exelência. A coleta de dados foi feita por meio de pesquisa bibliográfica utilizando-se de livros, artigos e sites. Como resultado desta pesquisa, ressaltamos que o Projeto Economia de Comunhão de Chaiara Lubich apresenta a perspectiva de uma prática cristã atenta às precariedades da vida humana como um dos sinais dos tempos de toda a história humana. $O$ carisma de Chiara assinala aspectos de vivências humana pautada no amor fraterno e constitue num verdadeiro convite a fugir da superficialidade da vivência cristã e encarnar o professado amor a Deus num gesto concreto de compromisso com o outro, sobretudo os mais pobres. A vivência do amor, é no entender de Chiara, condição para o verdadeiro conhecimento de Deus, "[...] aquele que não ama não conheceu a Deus, por que Deus é amor [...]" (1 Jo: 1,8).
\end{abstract}

Palavras-chave: Chiara Lubich. Economia de Comunhão. Humanização.

${ }^{16}$ Bacharel em Teologia pela Pontifícia Universidade Católica do Paraná. Contato: evertonluizdossantos@gmail.com

${ }^{17}$ Doutora em Teologia. Docente da Pontifícia Universidade Católica do Paraná (PUCPR). Contato: j.candiotto@pucpr.br 


\title{
TEOLOGIA E PSICANÁLISE: IMPLICAÇÕES DA TEOLOGIA DA PATERNIDADE DIVINA SOBRE A PSIQUE DEPRESSIVA
}

Autora: Fernanda Tramontini dos Santos ${ }^{18}$ Orientador: Waldir Souza ${ }^{19}$

\begin{abstract}
Resumo
Este artigo busca descrever como a espiritualidade católica pode interferir na psique depressiva, quando oferece Deus como Pai, num contexto de acréscimo significativo de casos da doença em todo o mundo e de fragilização da figura paterna no imaginário social.Traz por objetivo propor uma abordagem pastoral sadia com vistas ao acolhimento e cura dessas pessoas, oferecendoIhes uma teologia da paternidade divina ortodoxa, porém, adequada às suas realidades psíquicas. Para tanto, buscou-se: (I) descrever a participação dos pais na constituição da psique depressiva, segundo a psicanálise lacaniana de Maria Rita Kehl, em “O tempo e o cão" (2009); (II) identificar algumas teologias da paternidade vigentes; e (III) relacionar o semblante paterno/materno constituinte da psiquê depressiva com essas teologias, verificando o possível impacto que uma espiritualidade baseada nelas pode provocar. A metodologia empregada foi bibliográfica qualitativa aplicada com análise de conteúdo Os resultados são que, considerando as distorções provocadas pelos filtros de representação mental e/ou distorções da doutrina, algumas teologias podem reavivar aspectos doentios do semblante paterno (Pai de Jesus e Pai Criador) ou do materno (Pai da Aliança e Pai Ético). Já o Pai Misericordioso (Lc 15,11-32) pode promover uma espiritualidade que ressignifique o semblante paterno, fraco e ausente, e estabelecer limites ao Outro, encorajando o depressivo a partir rumo aos próprios desejos, ou seja, à cura. Conclui-se que para cada personalidade, sadia ou patológica, cabe uma espiritualidade personalíssima sendo que, no caso da depressão, implica à Igreja partir rumo aos doentes oferecendo-Ihes com gratuidade e alegria o banquete celestial.
\end{abstract}

Palavras-chave: Teologia da paternidade divina. Psicanálise. Depressão.

\footnotetext{
${ }^{18}$ Bacharela em Teologia pela Pontifícia Universidade Católica do Paraná. Contato: santoscatolicos.arte@gmail.com

19 Doutor em Teologia pela Pontifícia Universidade Católica do Rio de Janeiro (PUC/RJ). Docente da Pontifícia Universidade Católica do Paraná (PUCPR). Contato: waldir.souza@pucpr.br
} 


\title{
SURDO-GAGO CURADO MC 7,31-37: JESUS LIBERTA EM VISTA DA MISSÃO.
}

Autor: Francisco José Beserra 20 Orientador: Vicente Artuso ${ }^{21}$

\begin{abstract}
Resumo
Este trabalho estudo ao relato da cura do surdo e gago que fora trazido a Jesus por algumas pessoas. Neste relato é possível ver que Jesus atende o homem e faz a cura através de uma intervenção curativa que incluía o toque: Jesus tocou nos seus ouvidos e colocou da sua própria saliva na língua do enfermo. Isto demonstra a forma humana pela qual Jesus tratava as pessoas, além de enfatizar a sua empatia, sua compaixão e sua misericórdia pelas pessoas. Neste estudo nota-se que Jesus dá atenção ao enfermo, que era excluído da sociedade por causa da sua enfermidade. Jesus é, portanto, o representante de Deus que recebe os excluídos e ao mesmo tampo é também a porta de integração dessas pessoas marginalizadas na sociedade: uma vez curado o homem falava e ouvia distintamente, o que lhe permitiu integrar-se radicalmente na sociedade dos seus dias, ele que era um marginalizado.
\end{abstract}

Palavras-chave: Surdo. Gago. Enfermo. Cura. Jesus.

${ }^{20}$ Bacharel em Teologia pela Pontifícia Universidade Católica do Paraná.

${ }^{21}$ Doutor em Teologia pela Pontifícia Universidade Católica do Rio de Janeiro. Docente da Pontifícia Universidade Católica do Paraná (PUCPR). 


\title{
A COSMOVISÃO DE LUTERO E SUAS INTERCONEXÕES COM A BIOÉTICA
}

Autor: Itamar Marques da Silva ${ }^{22}$ Orientador: Waldir Souza ${ }^{23}$

\begin{abstract}
Resumo
Este artigo analisa a cosmovisão de Lutero e suas interconexões com a bioética. Tal abordagem se justifica pois, meio milênio após a Reforma, constata-se que algumas denominações cristãs, oriundas do movimento iniciado por Lutero, parecem percorrer um caminho inverso do Lutero libertador, apegando-se ao 'velho' Lutero pragmático, ignorando a essência cristã que aflorouse na igreja neotestamentaria, indo justamente ao encontro de uma falsa moral cristã, que por vezes oprime em nome da fé. Diante disso, o presente artigo tem como propósito identificar, em perspectiva latino-americana, pontos convergentes com a bioética na vida do Reformador. Para isso aplicou-se a metodologia dedutiva, qualitativa, descritiva e de revisão bibliográfica. Buscou-se assim, nas relações abscônditas entre o pensamento de Lutero e alguns princípios da Bioética a conexão com: informação, autonomia e justiça social, bem como, verificou-se no pensamento do Reformador uma provocação libertária em prol dos vulneráveis, que foi esquecida, em sua maioria, por aqueles que celebram Lutero na atualidade. Considera-se, portanto, que há em Lutero uma referência comum para as denominações que não possuem um magistério vertical. No entanto, é preciso celebrá-lo com algumas ressalvas, para não incorrer no erro de potencializar o personagem pragmático, notório a partir de seu alinhamento com a aristocracia, e continuar exilando a face libertária do Reformador.
\end{abstract}

Palavras-chave: Lutero. Teologia. Bioética. Moral cristã.

22 Bacharel em Teologia pela Pontifícia Universidade Católica do Paraná.

23 Doutor em Teologia pela Pontifícia Universidade Católica do Rio de Janeiro (PUC/RJ). Docente da Pontifícia Universidade Católica do Paraná (PUCPR). Contato: waldir.souza@pucpr.br. 


\title{
A MISSÃO EVANGELIZADORA EM CHIARA LUBICH
}

Autor: Ivanaldo Ferreiria De Araujo 24 Orientador: Joachim Andrade ${ }^{25}$

\begin{abstract}
Resumo
Este trabalho investiga a Missão Evangelizadora em Chiara Lubich. Tal abordagem se dá em razão das muitas dificuldades e dos desafios que a Igreja enfrenta para tratar da evangelização no mundo contemporâneo. Este estudo se faz necessário tendo em vista a busca da Igreja em encontrar possíveis soluções diante dos muitos desafios e obstáculos para essa missão. Nesse caminho, a grande esperança foi dada pelo Concílio Vaticano II, que apontou novas ideias e amenizou a crise pela qual passava a Igreja. O objetivo desta pesquisa é mostrar, embora modestamente, que o Carisma da Unidade, nascido da vida de Chiara Lubich, pode contribuir para a caminhada da evangelização da Igreja nos tempos atuais. O fio condutor foram as pesquisas bibliográficas, abalizando-se alguns escritos da Lubich e a relevância de perspectivas para a Nova Evangelização, segundo a própria experiência de Lubich enquanto cristã e fundadora do Movimento dos Focolares. A análise demonstrou, entre outras conclusões, a sucessiva busca da vivência do Evangelho no dia a dia em face de uma sociedade secularizada, individualista, permeada por uma cultura relativista que busca respostas imediatas. A experiência evangelizadora que sustenta o Movimento dos Focolares testemunha atitudes fundamentais para a missão catequizadora nos tempos atuais.
\end{abstract}

Palavras-chave: Missão. Nova Evangelização. Igreja. Chiara Lubich.

${ }^{24}$ Bacharel em Teologia pela Pontifícia Universidade Católica do Paraná. Contato: ivofaraujo@gmail.com

25 Doutor em Ciências da Religião pela Pontifícia Universidade Católica de São Paulo (PUC-SP). Docente da Pontifícia Universidade Católica do Paraná (PUCPR). Contato: joachimandrade@terra.com.br. 


\title{
A MISSÃO DA PASTORAL EDUCATIVA NAS ESCOLAS CATÓLICAS E OS SEUS DESAFIOS NA CONTEMPORANEIDADE
}

Autor: Jean Marcos Gregol Gwiazdecki ${ }^{26}$ Orientador: Cesar Leandro Ribeiro ${ }^{27}$

\begin{abstract}
Resumo
Este trabalho aborda a ação da Pastoral Educativa frente aos desafios da contemporaneidade. Seu principal objetivo é compreender a missão da Pastoral no ambiente das Escolas Católicas. Para tanto, utiliza-se do método dedutivo, a partir de consulta e pesquisa bibliográfica na literatura das áreas de educação, teologia e pastoral educativa. $\mathrm{O}$ artigo apresenta uma síntese do itinerário da evangelização no percurso histórico da Igreja, contextualiza a escola católica na realidade contemporânea e, por fim, reflete sobre o papel da Pastoral Educativa diante de todo esse contexto. Em sua conclusão o artigo aponta para os desafios e oportunidades que os sinais do tempo apresentam para a Igreja e a sua missão de educação-evangelizadora, considerando as inciativas pastorais do pontificado de Francisco.
\end{abstract}

Palavras-chave: Teologia. Educação. Evangelização. Pastoral Educativa.

${ }^{26}$ Bacharel em Teologia pela Pontifícia Universidade Católica do Paraná. Contato: jean.jmgg@gmail.com

${ }^{27}$ Doutor em Teologia pela Pontifícia Universidade Católica do Paraná (2018). Docente da Pontifícia Universidade Católica do Paraná (PUCPR). 


\title{
O ECUMENISMO NA SEGUNDA CONFERÊNCIA GERAL DO EPISCOPADO LATINO-AMERICANO EM MEDELLÍN
}

\author{
Autor: José Luiz da Silva Junior ${ }^{28}$
} Orientador: Elias Wolff ${ }^{29}$

\begin{abstract}
Resumo
Este artigo é resultado de pesquisas nos documentos referentes à Conferência do Episcopado Latino - Americano e Caribenho realizado em Medellín (1968), concatenado com as bibliografias de autores que comentam a respeito, de modo a analisar de que forma essa Conferência orienta o ecumenismo na ação evangelizadora da Igreja Católica na América Latina e no Caribe. Com esse propósito, o objetivo geral foi pesquisar como se apresenta o ecumenismo na II Conferência Geral dos bispos da América Latina e do Caribe e a sintonia com o concílio Vaticano II e o movimento ecumênico na América Latina. Para tanto o percurso contemplou analisar o conteúdo ecumênico presente nas Conclusões da Conferência de Medellín, bem como identificar os objetivos e as dimensões do ecumenismo nas Conclusões da Conferência de Medellín e, também, verificar quais são os principais desafios e as possibilidades para o ecumenismo na Igreja católica da América Latina a partir da Conferência de Medellín. Concretamente, este projeto se efetivou através de uma pesquisa que se caracteriza como bibliográfica qualitativa, numa abordagem analítica que visou obter e identificar, a partir do levantamento dos documentos das Conferências Gerais do CELAM e nos seus comentadores, a movimentação do diálogo ecumênico na região. Os resultados apresentados ficaram circunscritos aos textos do documento final, os quais, segundo os critérios de apreciação desta pesquisa, possuem inferências importantes em relação ao tema "ecumenismo". Nas considerações finais, o destaque fica por conta da participação na celebração eucarística dos observadores não-católicos, que foi o ponto alto na compreensão da substancial e efetiva presença destes convidados na discussão dos textos de Medellín que tratam do ecumenismo.
\end{abstract}

Palavras-chave: Conferência de Medellín; Ecumenismo; Concílio Vaticano II; Igreja

\footnotetext{
${ }^{28}$ Bacharel em Teologia pela Pontifícia Universidade Católica do Paraná.

${ }^{29}$ Doutor em Teologia pela Gregoriana de Roma. Docente da Pontifícia Universidade Católica do Paraná (PUCPR).
} 


\title{
PERFIL DO PLANEJAMENTO FAMILIAR QUANTO AO CONSENSO ENTRE OS PARCEIROS
}

\author{
Autora: Kathleen Vieira ${ }^{30}$ \\ Orientador: Mário Antônio Sanches ${ }^{31}$
}

\begin{abstract}
Resumo
Deus criou o homem e a mulher e ordenou que eles se multiplicassem e enchessem a terra, tornando-se assim partícipes da Criação. Para colaborar com a missão superior é necessário assumir uma paternidade responsável. Muitas vezes essa paternidade não ocorre, e apenas um membro do casal planeja o filho ou este nem mesmo é planejado. Objetivo deste trabalho é relacionar os índices de consenso entre os parceiros e a existência ou não de planejamento familiar. Quanto a metodologia utilizada, trata-se de uma pesquisa descritiva e analítica com abordagem quantitativa. Este estudo é parte de um projeto maior, por isso utiliza, parcialmente, um banco de dados fruto de pesquisa de campo efetivada a partir da aplicação do Instrumento de Pesquisa Planejamento da Parentalidade no Contexto da Bioética. Este instrumento de pesquisa foi elaborado e validado (SANCHES et al, 2015) e consta de 56 questões relacionadas ao planejamento familiar. Deste modo, esta pesquisa é parte de um projeto aprovado pelo Comitê de Ética em Pesquisa da PUCPR (Parecer: 770.977, de 27/08/2014). Os questionários foram aplicados em várias localidades do Estado do Paraná situadas em Apucarana, Campo Mourão, Curitiba, Jacarezinho, Londrina, São José dos Pinhas e Toledo. A pesquisa fora realizada em encontros organizados por instituições religiosas, educacionais e sociais entre 2014 e 2018, sendo $45 \%$ em encontros no âmbito religioso, $35 \%$ em encontros com pais de alunos em escolas e $20 \%$ em espaços sociais, como clubes de mães e associações de moradores. 0 critério de inclusão na pesquisa era ter ao menos um filho e de exclusão estar vivenciando uma gravidez no momento da pesquisa. $O$ banco de dados foi construído como um trabalho conjunto de vários membros do grupo de pesquisa. No total foram respondidos 2.196 questionários válidos relacionados à gravidez do primeiro filho. Os dados sistematizados com uso de software de análise estatística o SPSS (Statistical Package for the Social Sciences) foram comparados com dados encontrados na literatura. Os dados da pesquisa mostram que dentre os casais que planejaram e conceberam o primeiro filho em consenso recebem melhor a notícia da chegada, com alegria e satisfação, ao passo que aqueles pais que não se planejaram, recebem a notícia da gravidez com preocupação e incerteza.
\end{abstract}

Palavras-chave: Planejamento Familiar. Igreja Católica. Parentalidade.

\footnotetext{
${ }^{30}$ Bacharela em Teologia pela Pontifícia Universidade Católica do Paraná.

${ }^{31}$ Doutor em Teologia pela EST. Docente da Pontifícia Universidade Católica do Paraná (PUCPR).
} 


\title{
A TEOLOGIA DO LAICATO NA IGREJA CATÓLICA UCRANIANA NO BRASIL, A PARTIR DO CONCÍLIO VATICANO II
}

\author{
Autor: Marcos Antonio Nogas ${ }^{32}$ \\ Orientador: Cesar Leandro Ribeiro ${ }^{33}$
}

\begin{abstract}
Resumo
Este trabalho analisa o protagonismo dos fiéis leigos e leigas na Igreja Católica Ucraniana no Brasil, por meio de argumentos fundamentados nos documentos conciliares e pós-conciliares, do Concílio Vaticano II e nas orientações da igreja oriental, que discorrem sobre o tema. Tal abordagem se justifica, pois essa questão foi abordada no Concílio Vaticano II (1962-1965), que deixou como legado importantes documentos a respeito do assunto. Também a Igreja Católica Ucraniana, por meio de seu Arcebispado-mor, exortou os cristãos leigos e leigas a colocarem seus dons a serviço da Igreja. $O$ objetivo deste estudo é identificar os principais motivos que interferem na conscientização do protagonismo laical na Igreja Católica Ucraniana no Brasil. Este propósito foi possível a partir de pesquisa bibliográfica e por meio de pesquisa exploratória, realizada entre membros do ministério ordenado, pessoas de vida consagrada e cristãos leigos e leigas. A pesquisa de campo foi integralmente realizada por meios eletrônicos, usando a plataforma Qualtrics, o que possibilitou a integridade dos dados, sigilo e aplicação de ferramentas de análise das informações. O resultado demonstrou que existem ações propostas pela hierarquia da Igreja Ucraniana, alinhadas com as orientações dos documentos pósconciliares. Os respondentes da pesquisa apresentaram percepções distintas sobre os temas e, apesar do tema do protagonismo ser considerado importante, a figura do cristão leigo está intimamente ligada ao trabalho pastoral supervisionado.
\end{abstract}

Palavras-chave: Protagonismo. Leigos. Leigas. Concílio. Igreja Ucraniana. Paróquia Viva.

\footnotetext{
32 Bacharel em Teologia pela Pontifícia Universidade Católica do Paraná.

33 Doutor em Teologia pela Pontifícia Universidade Católica do Paraná (2018). Docente da Pontifícia Universidade Católica do Paraná (PUCPR).
} 


\title{
A NARRATIVIDADE COMO CAMINHO DE EVANGELIZAÇÃO INSPIRADA NA PREGAÇÃO DO PE LÉO - COMUNIDADE BETHÂNIA
}

Autora: Maria Aparecida Toledo Fortunato ${ }^{34}$

Orientador: Roberto Nentwig ${ }^{35}$

\begin{abstract}
Resumo
O artigo trata do tema da narratividade como caminho de evangelização, inspirando-se na pregação do padre Léo - Comunidade Bethânia. Consideramos que a narrativa é uma ferramenta muito atual e eficaz para se proclamar o Evangelho. O trabalho parte da contação de histórias, um recurso de comunicação que perpassa as culturas e é altamente positiva como expressão verbal. Posteriormente, aborda-se a narratividade na evangelização, tendo em conta que a Revelação é a narrativa da história de Deus com o seu povo, especialmente a vida de Jesus de Nazaré. O artigo traz, por fim, a figura do Padre Léo, um sacerdote que revolucionou a maneira de evangelizar pela narrativa: um pregador alegre e irreverente, que contava piadas, causos ao modo mineiro, dançava, cantava, sempre bem fundamentado nas Sagradas Escrituras. O objetivo final, portanto, é mostrar como a pregação deste personagem traz luzes para uma evangelização narrativa, seguindo o exemplo de Jesus, que anunciou o Reino através de parábolas.
\end{abstract}

Palavras-chave: Contação de Histórias. Narratividade. Evangelização. Pregação. Padre Léo.

\footnotetext{
${ }^{34}$ Bacharela em Teologia pela Pontifícia Universidade Católica do Paraná.

35 Doutor em Teologia pela PUC-RJ (2017). Docente da Pontifícia Universidade Católica do Paraná (PUCPR) e do Studium Theologicum em Curitiba. Contato: beto.catequese@gmail.com.
} 


\title{
O SÍNODO DA AMAZÔNIA NA PERSPECTIVA ECOFEMINISTA LATINO AMERICANA
}

\author{
Autora: Maria Cristina Cachova de Paiva ${ }^{36}$ \\ Orientadora: Jaci de Fátima Souza Candiotto ${ }^{37}$
}

\begin{abstract}
Resumo
Considerando que a realidade planetária está ameaçada pelo processo de entropia provocada pela intervenção humana, que desconsidera a sacralidade da vida e a realidade de sofrimento das mulheres em decorrência da mentalidade patriarcal, a proposta deste artigo é pontuar aspectos convergentes entre a reflexão teológica ecofeminista, e o Sínodo da Amazônia que pode efetivamente contribuir para ações afirmativas de superação da mentalidade patriarcal, marcada pelo dualismo que associa homem à cultura e mulher à natureza, tendo como consequência legitimar a explorar de ambas. O propósito será conseguido a partir da pesquisa bibliográfica e documental, com especial atenção ao documento sinodal e pós sinodal. A análise dos documentos postulou muitas luzes para a superação dessas grandes problemáticas assinaladas, exaltando a necessidade de uma conversão em muitos sentidos, como meio para se alcançar uma ecologia integral. E, para a teologia ecofeminista, é condição sine qua para um mundo sustentável, a supuração dos dualismos, que tem sustentado hierarquias de dominação e exploração tanto da natureza quanto das mulheres.
\end{abstract}

Palavras-chave: Sínodo. Amazônia. Ecofeminismo.

\footnotetext{
${ }^{36}$ Bacharela em Teologia pela Pontifícia Universidade Católica do Paraná. Contato: cachovadepaiva@gmail.com

${ }^{37}$ Doutora em Teologia. Docente da Pontifícia Universidade Católica do Paraná (PUCPR). Contato: j.candiotto@pucpr.br
} 


\title{
A CRENÇA NO PURGATÓRIO APÓS O CONCÍLIO VATICANO II
}

Autor: Mario Malechi ${ }^{38}$ Orientador: Cesar Leandro Ribeiro ${ }^{39}$

\begin{abstract}
Resumo
Este trabalho, sob o título a Crença no Purgatório após o Concílio Vaticano II, faz uma abordagem da Doutrina Escatológica, a qual do ponto de vista teológico tem gerado para muitos um campo de estudos intangível. O objetivo é analisar o purgatório contemplando uma clarificação histórica mais contundente em sua significação, como dogma para uma atualização de suas atribuições doutrinárias. O purgatório é aqui descrito, de modo geral, sobretudo a partir do pensamento de Renold Blanck, como um estado intermediário das almas que alcançaram a salvação, necessitando ainda de uma purificação final; trata-se de um sinal de esperança na última oferta de misericórdia de Deus após a morte. $O$ artigo trabalha na intenção de apresentar o purgatório dentro de suas reais atribuições doutrinais dogmáticas, em que a teologia pós Concílio Vaticano II apresenta uma atualização e revitalização.
\end{abstract}

Palavras-chave: Purgatório; Escatologia; Esperança; Vaticano II

${ }^{38}$ Bacharel em Teologia pela Pontifícia Universidade Católica do Paraná.

39 Doutor em Teologia pela Pontifícia Universidade Católica do Paraná (2018). Docente da Pontifícia Universidade Católica do Paraná (PUCPR). 


\title{
SINODALIDADE: A IGREJA SEVIDORA DO TERCEIRO MILÊNIO
}

Autora: Marisol Gabasa Barrachina ${ }^{40}$ Orientador: Miguel Fernando Rigoni ${ }^{41}$

\begin{abstract}
Resumo
Este trabalho, propõe destacar a importância do agir nos tempos atuais, como Povo de Deus de forma sinodal. Através de pesquisa e releitura das características das primeiras comunidades cristãs e dos documentos conciliares do Vaticano II e pós conciliares. Com destaque para a particularidade do Papa Francisco e sua teologia "sempre reformada", que identifica as necessidades do povo de Deus no terceiro milênio, do caminhar juntos na práxis da escuta e do discernimento desde as estruturas clericais até as comunidades particulares respeitando a forma multifacetada do atual cristão. A sinodalidade contribui para que o povo de Deus tenha uma co-protagonismo na missão evangelizadora, com diretrizes responsáveis que trazem mudanças às grandes questões do mundo moderno. Refletindo sobre a recente experiência do Sínodo da Amazônia, pode-se concluir que a sinodalidade sob ação do Espírito Santo, trouxe para estudo, futuras mudanças assuntos essenciais para o caminhar da Igreja de forma a se identificar como verdadeira encarnação de Cristo na história.
\end{abstract}

Palavras-chave: Sinodalidade. Povo de Deus. Papa Francisco.

40 Graduada em Administração (UFPR), Pós Graduada em Finanças (FAE) e Bacharela em Teologia pela Pontifícia Universidade Católica do Paraná.

${ }^{41}$ Doutor em Teologia (PUCPR). Docente da Pontifícia Universidade Católica do Paraná (PUCPR). 


\title{
MANIFESTAÇÃO DO ESPÍRITO SANTO: UNÇÃO E/OU EMOÇÃO.
}

Autora: Maysa Muniz de Melo Jorge Gonçalves ${ }^{42}$ Orientador: Marcio Luiz Fernandes ${ }^{43}$

\begin{abstract}
Resumo
A manifestação do Espírito Santo ou o Batismo com/no Espírito Santo ocorreu no pentecostes e apresenta seu relato no Livro de Atos, capítulo 2. Nos dias de hoje Igrejas conhecidas como pentecostais, buscam e pregam o reviver dessa manifestação. Com a expansão do movimento pentecostal, certas manifestações se tornaram objeto de observação e questionamento por suas reações externadas, que aproximam-se muito de performances teatrais. Esta pesquisa visa analisar e comparar as manifestações descritas em Atos e nos dias de hoje, e com o auxílio de outras ciências, refletir sobre a relação do sobrenatural com as emoções, e o lugar da emoção na experiência religiosa cristã pentecostal e sua relevância na vida relacional do indivíduo.
\end{abstract}

Palavras-chave: Espírito Santo. Manifestação. Atos. Pentecostal.

42 Bacharela em Teologia pela Pontifícia Universidade Católica do Paraná.

43 Doutor em Teologia pela Pontifícia Universidade Lateranense - Doutor em Psicologia pela USP. Docente da Pontifícia Universidade Católica do Paraná (PUCPR). 


\title{
CORPOREIDADE E CUIDADO: INTERFACES ENTRE TEOLOGIA E BIOÉTICA
}

Autor: Michel Eriton Quintas ${ }^{44}$

Orientador: Waldir Souza ${ }^{45}$

\begin{abstract}
Resumo
A sociedade atual está marcada pelo paradigma da tecnologia, da técnica e da biotecnociência. O corpo, no que lhe concerne, relaciona-se com este contexto. Assim, com o objetivo de reconhecer os pressupostos éticos que podem contribuir no debate sobre as dificuldades e limites relacionadas ao poderio biotecnocientífico, que não deve intervir de maneira irrestrita no corpo, o presente artigo dialoga com as categorias de corporeidade e cuidado nas interfaces entre Teologia e Bioética. Para tanto, faz-se necessário um itinerário de construção de um panorama que contemple: a antropologia teológica; os diferentes olhares sobre a corpo na história; e a superação dos dualismos, fomentando equilíbrio e perspectivas integrais do ser humano. A metodologia empregada é bibliográfica com análise de conteúdo. O método, por sua vez, contempla pesquisas qualificadas nos campos da Antropologia Teológica, da Bioética e das análises da sociedade hodierna. Conclui-se, então, que cuidar do próprio corpo e do corpo do outro são tarefas essencialmente cristãs e urgentes em Bioética. Por fim, importa mencionar que o presente trabalho se insere numa perspectiva de aprofundamento, sobretudo pela necessidade de segmentação do conhecimento para responder aos complexos problemas contemporâneos.
\end{abstract}

Palavras-chave: Corpo. Cuidado. Antropologia teológica. Bioética.

\footnotetext{
${ }^{44}$ Bacharel em Teologia pela Pontifícia Universidade Católica do Paraná. E-mail: michel.quintas@pucpr.edu.br

${ }^{45}$ Doutor em Teologia pela Pontifícia Universidade Católica do Rio de Janeiro (PUC/RJ). Docente da Pontifícia Universidade Católica do Paraná (PUCPR). Contato: waldir.souza@pucpr.br.
} 


\section{VIDA, MORTE E RESSURREIÇÃO}

Autora: Nilse Rosa de Siqueira ${ }^{46}$ Orientador: Ildo Perondi ${ }^{47}$

\section{Resumo}

Este estudo desenvolve uma reflexão sobre a visão da vida, morte e ressurreição. A razão deste trabalho é justamente destacar os tópicos relacionados ao tema e mencionar as profecias da vida, morte e ressurreição de Cristo e da vida humana como mistério unificador de toda a nossa fé, com o objetivo de analisar o desenvolvimento dos estudos, nos livros e nas Sagradas Escrituras, que refletem mais a relação entre a vida e a morte, e a suposta continuidade da vida. Por meio de pesquisa bibliográfica, o estudo mostrou a importância da crença em situações referentes à espiritualidade e nas quais se apresenta o sentido do sagrado, a vida cristã e as obras de Deus para o significado pessoal. Em seguida o trabalho se direciona para a fé depositada na vida, morte e ressurreição de Jesus Cristo, a partir da abordagem segundo 1Cor 15, em que o apóstolo Paulo procura solucionar as dúvidas que a comunidade de Corinto tinham em relação à ressurreição dos mortos e que continuam em muitos ambientes de hoje. A fundamentação bíblica sobre o tema da ressurreição torna-se fonte de esperança para todas as pessoas cristãs, em todos os tempos, e fonte de iluminação também para as pessoas que hoje carregam a cruz de cada dia.

Palavras-chave: Vida. Morte. Ressurreição. Espiritualidade.1Coríntios.

${ }^{46}$ Bacharela em Teologia pela Pontifícia Universidade Católica do Paraná.

${ }^{47}$ Doutor em Teologia. Docente da Pontifícia Universidade Católica do Paraná (PUCPR). 


\title{
TEOLOGIA E CULTURA MIDIÁTICA CONTEMPORÂNEA: ENSINO RELIGIOSO ATRAVÉS DA EDUCAÇÃO A DISTÂNCIA
}

Autora: Regina de Holanda Gamboa Almeida 48 Orientador: Miguel Fernando Rigoni ${ }^{49}$

\begin{abstract}
Resumo
O presente artigo propõe o uso da metodologia de educação a distância como forma de auxiliar o ensino religioso e disseminar a tolerância religiosa. Partindo de uma análise do relacionamento da Igreja Católica Apostólica Romana com os meios de comunicação em massa, principalmente com o marco anual do Dia Mundial das Comunicações Sociais, foi possível constatar uma abertura contínua e crescente da instituição para as novas tecnologias e canais midiáticos, em prol da evangelização. Em conjunto com essa análise, um diagnóstico sobre o panorama da realidade do ensino religioso brasileiro, apontou que é necessário soluções que ajudem a combater a intolerância religiosa dentro da sala de aula. Dessa forma, é proposto o aplicativo de smartphones Religare, que utiliza-se da metodologia EaD para expor as diferentes religiões da cultura brasileira, com a premissa de difundir a tolerância religiosa ao comparar as simbologias que se assemelham entre as diversas religiões.
\end{abstract}

Palavras-chave: Concílio Vaticano II. Dia Mundial das Comunicações Sociais. Ensino religioso. Intolerância religiosa. Educação a distância.

\footnotetext{
${ }^{48}$ Bacharela em Teologia pela Pontifícia Universidade Católica do Paraná. Contato: regina.hgamboa@hotmail.com

49 Doutor em Teologia (PUCPR). Docente da Pontifícia Universidade Católica do Paraná (PUCPR). Contato: miguelrigoni@gmail.com
} 


\title{
SIMONE WEIL: A DESCRIAÇÃO HUMANA EM UMA DIMENSÃO KENÓTICA
}

Autora: Silvana de Oliveira Sitarz ${ }^{50}$ Orientadora: Andréia Cristina Serrrato ${ }^{51}$

\begin{abstract}
Resumo
Este trabalho descreve a mística da Kenósis em Simone Weil (1909-1943). Tal abordagem se faz necessária como meio de transformação para o ser humano, de modo que ao fazer a experiência do sofrimento do outro, este possa ser resignificado pela graça de Deus, processo que possibilita um esvaziamento de si. A finalidade deste estudo encontra-se em apresentar a mística kenótica de Weil não como "fuga do mundo", assim entendida por muito tempo, mas como integração do ser humano à sociedade. Este propósito será conseguido a partir da revisão bibliográfica básica estratégica, utilizando como apoio e referência principal "Espera de Deus" e "O Enraizamento", escritos por Weil. Considerando que em Weil a sua experiência se deu em uma busca intensa pela verdade, totalmente a margem de uma religião institucionalizada, sua experiência de encontro com o sagrado aconteceu em um processo Kenótico. Assim afirmamos que a não participação em uma Instituição religiosa não impede a pessoa de realizar a experiência mística de encontro profundo com o Senhor da Vida e nem a torna descrente. Uma procura de sentido incansável a ponto de perceber que a busca de Deus se torna espera de Deus experimentada na Graça.
\end{abstract}

Palavras-chave: Simone Weil. Mística. Graça.

${ }^{50}$ Bacharela em Teologia pela Pontifícia Universidade Católica do Paraná. Contato: silvanasitarz@gmail.com

${ }^{51}$ Doutora em Teologia pela Pontifícia Universidade Católica do Rio de Janeiro (2015). Docente da Pontifícia Universidade Católica do Paraná (PUCPR). Contato: andreia.serrato@pucpr.br. 


\title{
O PARADOXO DO MATRIMÔNIO CRISTÃO: ENTRE O PERENE E O EFÊMERO
}

\author{
Autor: Silvio Sant'Ana Leandro ${ }^{52}$ \\ Orientadora: Jaci de Fátima de Souza Candiotto ${ }^{53}$
}

\begin{abstract}
Resumo
Este artigo cientifico descreve a contradição que ocorre no relacionamento matrimonial cristão, que muitos ao realizar sua promessa e aliança conjugal apresentam o desejo de uma relação duradoura, mais diante das dificuldades e tensões que aparecem na relação, cada vez mais os laços e alianças de compromissos estáveis, tornam-se efêmero e muitos, não sobrevive por um longo período de tempo. No artigo há um elenco de situações que em nossa atualidade tem uma forte interferência na relação matrimonial, como por exemplo: o trabalho, o progresso da ciência, o acesso ao conhecimento e educação, a condição da mulher e a queda dos valores tradicionais e a busca constante do novo. É explorado o matrimônio como uma comunhão de vida e a semelhança com a comunhão da Santíssima Trindade. É levantada a possibilidade de ajudar a comunhão conjugal através de um caminho espiritual personalizado para o casal, explorando seus dons e carismas para superar os desafios de uma vida conjunta. São apresentadas as reflexões da Igreja através dos documentos Amoris Laetitia, Familiaris Consortio, Christus Vivit, Gaudium et spes e Mulieres Dignitatem para ajudar as famílias e os relacionamentos a melhor compreender o momento e a viver com maior alteridade as relações conjugais e familiares.
\end{abstract}

Palavras-chave: Matrimônio, Igreja, Espiritualidade, atualidade.

52 Bacharel em Teologia pela Pontifícia Universidade Católica do Paraná. Contato: silviosantleandro@gmail.com

${ }^{53}$ Doutora em Teologia. Docente da Pontifícia Universidade Católica do Paraná (PUCPR). Contato: j.candiotto@pucpr.br 


\section{O MINISTÉRIO PRESBITERAL EM QUESTÃO}

Autora: Solange de Oliveira dos Santos ${ }^{54}$ Orientador: Roberto Nentwig ${ }^{55}$

\section{Resumo}

Este trabalho resgata a identidade do ministério presbiteral de um modo contextualizado. 0 artigo tem os seguintes objetivos: refletir sobre a identidade e exercício do ministério presbiteral na Igreja Católica no contexto atual; traçar breve panorama dos desafios da vida presbiteral diante da mudança de época e apontar luzes para o exercício ministerial na atualidade. Adotouse a metodologia histórico-indutiva e descritiva. A revisão bibliográfica se deu a partir de documentos da Igreja, livros de especialistas na temática e arquivos de revistas impressas e online. A pesquisa apontou para a necessidade de um resgate da teologia pós conciliar do ministério ordenado, diante de tentaivas de interpretá-lo de modo anacrônico. Além disso, elencamos alguns desafios e conflitos, tais como: psicoafetividade, homoafetividade, celibato, abusos sexuais, carreirismo, clericalismo, síndrome de Burnout, entre outros. As autoridades eclesiásticas têm sido desafiadas a enfrentar com coragtem tais problemáticas. Concluiu-se que a crise que assombra a Igreja não lhe é exclusiva, pois o momento contemporâneo é marcado pela crise institucional. Faz-se necessário considerar o presbítero como um ser humano, em toda sua integralidade. A própria Igreja é responsável, com a luz do Espírito, para formá-lo e cuidálo, além mudar estruturas que ajudem a aprimorar o exercício ministerial.

Palavras-chave: Ministério presbiteral. Identidade. Crises/conflitos.

\footnotetext{
${ }^{54}$ Bacharela em Teologia pela Pontifícia Universidade Católica do Paraná. Contato: sololisantos@gmail.com.

55 Doutor em Teologia pela PUC-RJ (2017). Docente da Pontifícia Universidade Católica do Paraná (PUCPR) e do Studium Theologicum em Curitiba. Contato: beto.catequese@gmail.com
} 


\title{
O SACRAMENTO DO MATRIMÔNIO E OS (RE)CASADOS: NOVAS FRONTEIRAS PASTORAIS, POSSIBILIDADES E LIMITES
}

\author{
Autora: Terezinha Roesler ${ }^{56}$ \\ Orientador: Miguel Fernando Rigoni ${ }^{57}$
}

\begin{abstract}
Resumo
O texto apresentado aborda aspectos relacionados ao sacramento do matrimônio para a Igreja Católica Apostólica Romana, enfatizando a situação dos casais recasados. Tal estudo se faz necessário diante das transformações sociais ocorridas na contemporaneidade, as quais vêm modificando as estruturas familiares. Nesse sentido, apontam-se novos caminhos de acolhimento aos casais recasados, através dos ensinamentos da Igreja, a fim de que esses fiéis cristãos possam participar da vida eclesial de forma completa. As discussões contemplam uma reflexão metodológica de análise bibliográfica e documental com o objetivo de fazer uma releitura a respeito das formas de enfrentamento das situações que envolvem os casais divorciados e separados. Para tanto, discute-se como a Igreja concebe o casamento, destacase a atuação pastoral no acolhimento e bem estar das famílias, incluindo os casais recasados, e apresenta a recente Pastoral Judiciária, que surge da reforma do processo de nulidade matrimonial, realizada pelo Papa Francisco depois do Sínodo Extraordinário da Família, que ocorreu no ano de 2014. A pesquisa evidenciou a existência de diversas ações eclesiais que se destinam a conduzir os casais recasados para participarem da vida cristã no interior de suas comunidades.
\end{abstract}

Palavras-chave: Matrimônio. Casais recasados. Pastoral judiciária.

\footnotetext{
${ }^{56}$ Bacharela em Teologia pela Pontifícia Universidade Católica do Paraná.

${ }^{57}$ Doutor em Teologia (PUCPR). Docente da Pontifícia Universidade Católica do Paraná (PUCPR).
} 


\title{
A LAUDATO SI NA FORMAÇÃO DAS PROFESSORAS E DOS PROFESSORES DE ENSINO RELIGIOSO
}

\author{
Autor: Tiago Trevisan ${ }^{58}$
}

Orientador: Elias Wolff ${ }^{59}$

\begin{abstract}
Resumo
O artigo aborda a temática "Cristianismo e ecologia: a Laudato Si na formação das professoras e dos professores de ensino religioso". Tal pesquisa insere-se em uma perspectiva que busca, considerando a reflexão do cristianismo sobre a urgência do cuidado com a casa comum, apontar elementos importantes que permitam aos professores e às professoras de ensino religioso realizarem uma prática pedagógica transformadora, visando construir uma cidadania ecológica. O objetivo do artigo é analisar de qual modo a teologia cristã, na sua relação com a ecologia, fundamentada na perspectiva apresentada na Laudato Si, pode auxiliar oferecendo luzes na formação continuada dos professores e das professoras de ensino religioso. Assim, construiu-se a dimensão teórica, através de coletas de materiais com indicações de fontes em livros, revistas especializadas, artigos científicos, Bíblia, exortações apostólicas, encíclicas e no Concílio Vaticano II. Como resultado destaca-se a urgência do cuidado com a casa comum, que é responsabilidade de toda a família humana. Toda a reflexão, se insere na linha da ecoteologia, que propicia o diálogo e a construção de pontes, visando o bem comum. $O$ ensino religioso escolar, de fato é um espaço privilegiado para tais abordagens. Para tanto, ao inserir a dimensão ecológica da fé cristã na formação continuada, pode-se assim superar o saber ingênuo, de modo a construir novas práticas pedagógicas e efetivar a transformação, a qual tem por base as ações cotidianas e a maturação de novos hábitos, superando a necessidade desacerbada pelo consumir, pelo ter, pelo prazer e pelo poder.
\end{abstract}

Palavras-chave: Fé cristã. Ecoteologia. Ensino religioso.

\footnotetext{
58 Bacharel em Teologia pela Pontifícia Universidade Católica do Paraná.

${ }^{59}$ Doutor em Teologia pela Pontificia Universidade Gregoriana (2000). Docente da Pontifícia Universidade Católica do Paraná (PUCPR).
} 


\title{
A JUSTIÇA SOCIAL NO PROFETA AMÓS
}

Autora: Veranilde Alves Costa Loch ${ }^{60}$ Orientador: Alceu Luiz Orso ${ }^{61}$

\begin{abstract}
Resumo
O profeta é aquele que é instrumento de Deus, a voz de Deus, aquele que vê as injustiças e as denuncia, chama para a realidade os opressores e os adverte de que não adianta oferecerem sacrifícios para Deus e colocarem uma carga muito grande aos vulneráveis. Amós, chamado de o Profeta da Justiça e do Direito, em seu tempo, em seu contexto teve o que o povo hebreu teve, o que Jesus Cristo teve: a preocupação com os mais vulneráveis: os órfãos, as viúvas e os estrangeiros. $E$ que estes mesmo opressores busquem a Deus em sua essência e deixem a corrupção, a imoralidade e deixem de esmagar o pobre, fazendo com que se desviem; assim o Livro do Profeta Amós tendo o caráter de Deus, é um grito profético em favor da justiça e da retidão; também diz claramente quão abominável é para Deus a oração e sacrifícios e rituais separadas da conduta reta. Na atualidade temos vários profetas que denunciam a exploração, a injustiça e o direito social. Temos os Papas, que traves da Tradição de Igreja Católica, pela ação do Espírito Santo, trazem documentos fortes sobre as injustiças sociais e, orientando assim, como ser cristão. Temos os mártires, como a Irmã Dorothy Mae Stang, assassinada no Estado do Pará, por defender os sem-terra. Temos nas Pastorais Sociais, Dom Helder Câmara que lutou por a dignidade do ser humano e como não falar na Dra. Zilda Arns Neumann, fundadora da Pastoral da Criança e da Pessoa Idosa.
\end{abstract}

Palavras-chave: Justiça, Direito, Religião, Vulneráveis.

${ }^{60}$ Bacharela em Teologia pela Pontifícia Universidade Católica do Paraná.

${ }^{61}$ Doutor em Teologia pela Pontifícia Universidade Católica do Paraná. Docente da Pontifícia Universidade Católica do Paraná (PUCPR). 